\title{
NATIONAL SECURITY STRATEGY OF THE NETHERLANDS: AN INNOVATIVE APPROACH ${ }^{1}$
}

\author{
Michel RADEMAKER
}

\begin{abstract}
The defence and security community is faced with deep uncertainty. Strategic planning can no longer be performed in the traditional way. External and internal security are closely interlinked and this means that security planning should be organised in a more interlinked manner too. This article describes how a national security strategy is being developed in the Netherlands in a strongly interagencyoriented way. Not threat driven but values and capabilities oriented. This is a very innovative and challenging process that is underway at the moment. Attention in this article is paid to the process and methodology to realise the strategy.
\end{abstract}

Keywords: National security, security strategy, risk assessment, strategic planning.

Politicians, security policy makers and military are all faced with deep uncertainty related to the future security environment. Both external and internal security are closely interlinked. Another issue is that during the last fifty years the governments have become bigger and bigger and the security-related knowledge and capacity have been stove-piped tremendously. Most stovepipes understand 'safety' but lack real understanding of security. A lot of real security challenges on the other hand do not stop at a stovepipe.

Governments want to spend more money on security-related issues initiated by events around the world pinpointing the theme as urgent (9/11, Madrid, London, Bali, Iraq etc.), but politicians miss useful instruments balancing the security investments (Joint Strike Fighter vs. Water or Energy or Pandemics).

Also a lot of the debating is too institutional. The debate is about power instead of capabilities. And compared to NATO-wide defence planning there are no equivalents in international fora for strategic security planning.

So, we witness that security plays a more central role again; there is a need for government-wide approaches (which are conspicuously lacking) by breaking through the stovepipes. 


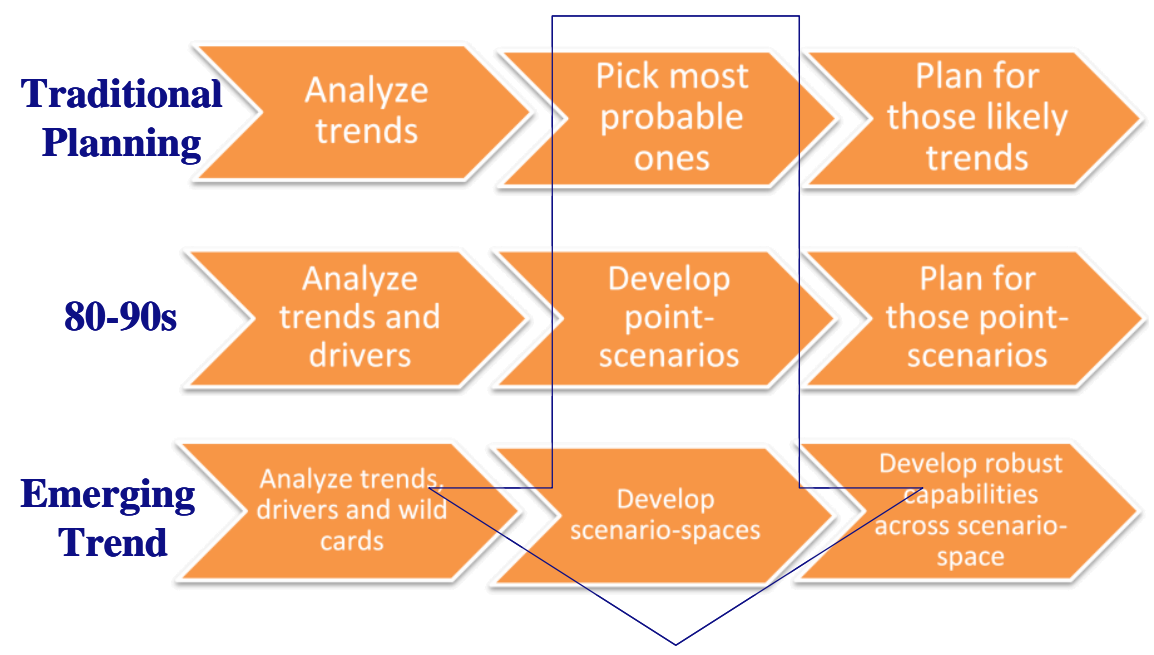

Figure 1: Trend Development in Strategy Making.

The conclusion is that we 'lost' the 'big picture.' And more, that "nobody really knows what strategy is." "Despite the obvious importance of strategy and despite the decades of academic research on the subject, there is surprisingly little agreement on what a strategy really is or how to develop a good one."3

The current approach to 'strategy' is still heavily tainted by the traditional approaches of the 1950s-60s: 'systematic,' 'rational' strategic policy planning in (especially) defence (after the former US Secretary of Defense Robert McNamara) and business management: define aims and purposive planning - 'deliberate planning' in Mintzberg's terminology (traditional approach). ${ }^{4}$ There is a major break in this trend in the 1980s-90s: in that period there is a heavy criticism on traditional 'strategic planning' even though it remains present (and heavily contested) both in the academic literature (both in business and in security) and in reality (e.g. petrochemical industry) - "the evidence points less to a 'decline of strategic planning' (Mintzberg) ${ }^{5}$ than to fundamental changes in the ways companies undertake their strategic planning. Also, in defence there is a criticism on threat-based planning, trends are shown towards assumption-based planning, and more recently towards capability-based planning.

Until recently there was a heavily contested debate in the literature between two schools: 'strategy as design' vs. 'strategy as process.' The 'design'-school sees strategy as a logical, aim-focused, purposive process with substantive choices that have to guide processes. The 'process'-school sees strategy as less structured process, more focused on agile processes that are robust against more uncertainty than on (brittle) 
substantive choices. The debate is not entirely decided but contours of a new consensus arise.

The debate is caricaturised in reality - in reality both dimensions are required. Also there are still discussions (both among thinkers and doers) about the appropriate 'mix' of purposiveness and agility: "In essence, strategy has an intended, emergent, and realized component" (Mintzberg - also accepted by him). ${ }^{6}$

There are a number of uncontested points (for strategic planning in deeply uncertain and quickly changing contexts): the traditional approach towards strategy (aim to means) is outdated; flexibility more important (and more difficult) than purposiveness; there is a need for more modesty in strategic planning; a mix of top-down (broad-stroke - e.g. commander's intent, strategic vision/mission, 'strategic direction') and top-down (underlying 'strategies' - by divisions, decentralized authorities, services, etc.) is necessary; we have to go from forecasting to foresight.

\section{Capability-Based Planning}

"Strategic planning relies on a capabilities-based approach, also known as capabilitybased planning (CBP). This approach is not geared towards one specific threat or risk. Rather it focuses on what is necessary to prevent the consequences of threats or risks as much as possible (prevention) and/or to be prepared (preparation and response). It is a flexible approach: tasks and capabilities can be used in this approach to withstand various threats. The capabilities-based approach derives its rationale from the increased diversity in the threat picture. The changing and more diffuse threat picture was cause for the Netherlands Ministry of Defence to no longer work with specific threats, but to base defence planning on the CBP method. Countries like Canada, the United States, the United Kingdom and Australia apply this method in the realisation of their strategic security policy; internationally, the capabilities-based approach is seen as a tried and tested method to anticipate diverse threats government-wide, across sectors and flexibly."7

There are many parallels with the literature on capabilities-based planning in defence and increasingly also homeland security. And there is a very obvious disconnect between this literature and most of the existing national security strategies. This is certainly the case in the US and the EU; you will find better examples in Canada and the UK, which do not have an explicit national security strategy but devote much attention to strategic planning methods.

The analysis of both the existing strategies and the analytical literature leads to a different structure for a National Security Strategy (NSS). The NSS should become the (relatively 'thin') capstone document of a pyramid of strategic documents. The NSS itself contains the following elements: a general enunciation of the basic interests and 
values the government subscribes to; a government-wide methodology for national security planning; underneath this capstone document the relevant players can then develop some functional (sub)-strategies in a bottom-up way, but based on the method and principles enunciated in the NSS, for example, a national energy-strategy, CBRN strategy, etc.

So, we see that security plays a more central role again (degree and timing correlated with incidents); there is a need for government-wide approaches (which are conspicuously lacking) - breaking through the stovepipes. For that a changing concept of 'strategy' is necessary. We should make a shift from 'design' to 'design'+'process' (as Mintzberg says: "strategy has an intended, emergent, and realized component") ${ }^{8}$ and towards a modular approach of strategic documents (hierarchy). We also see a trend towards capabilities-based planning and new ways of dealing with the future (from forecast to foresight, from point scenarios to scenario-spaces). And on top of that, more emphasis is put on risk assessment.

All these elements need to be incorporated in the new NSS, while most current national security strategies do not reflect these important changes.

\section{Critical Interests}

Thus, a lot of changes are apparent, but the process begins with a definition of security or, more precisely, national security. Until not so long ago, in the Netherlands, it was defined as protecting the international order and the democratic order. But these are instruments and not goals and they lack any focus on policy development or risk assessment balancing.

National security is protected when critical interests and values are taken care of.

A critical interest is decisive for the upkeeping of territorial, physical, economic and ecological security and social and political stability. When these interests (partly) are neglected or disturbed, the functioning of the state and society are potentially or actually in danger.

Consequently, the NSS $^{9}$ is based on the following five interests:

- Territorial Security: the undisrupted functioning of the Netherlands as an independent state, and more specifically the territorial integrity of the country. The territorial integrity is at risk in the event, for example, of a threatened occupation of the state territory by another state, but also in the event of a terrorist attack.

- Economic Security: the undisrupted functioning of the Netherlands as an effective and efficient economy. For example, economic security can be breached if trade with an important foreign partner is lost. 


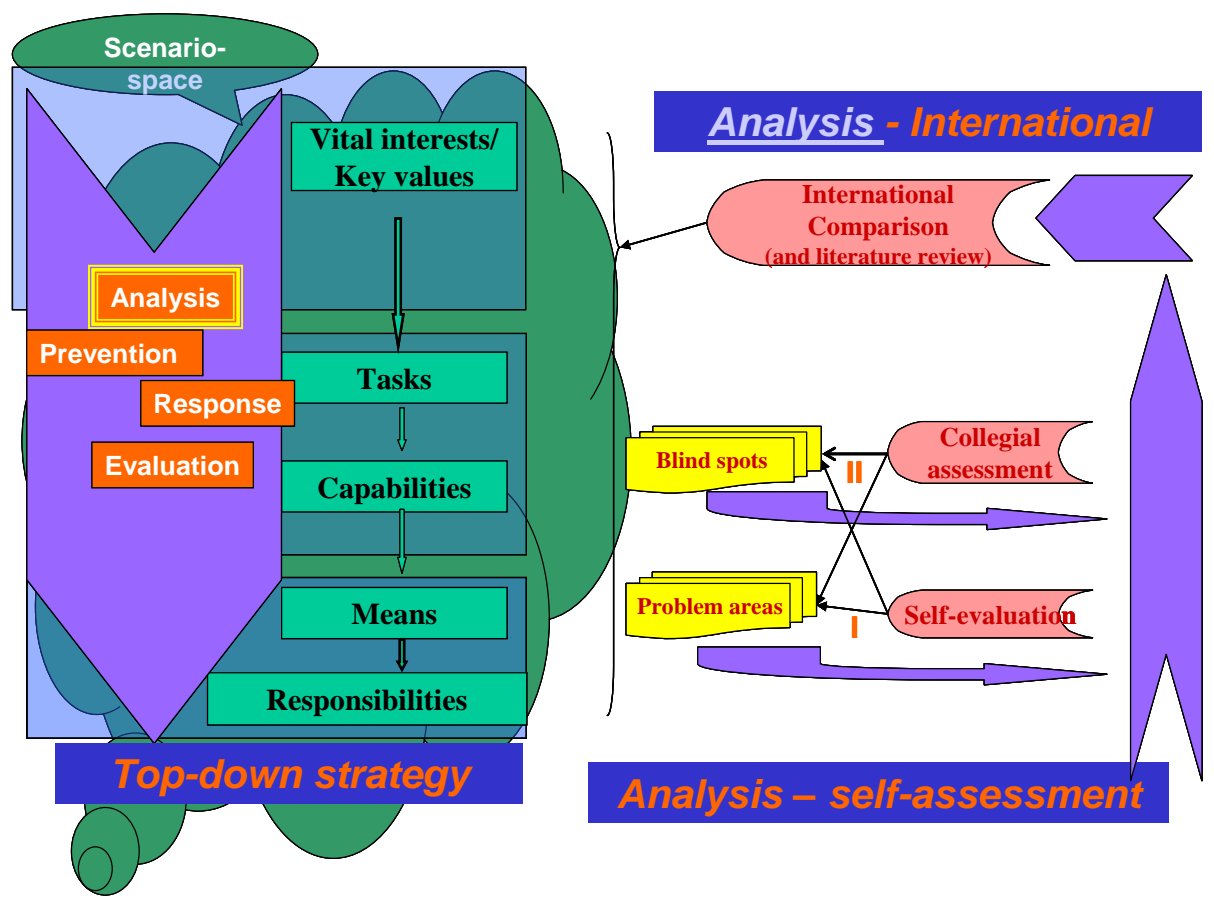

Figure 2: The Steps of the Strategy Development Approach.

- Ecological Security: sufficient self-recovery capability of the living environment in the event of breach. Ecological security can be at risk due to, e.g., disruptions in the management of the surface water, but also due to climate changes.

- Physical Security: the undisrupted functioning of humans in the Netherlands and its (living) environment. Physical security can be under pressure if, e.g., public health is threatened by an epidemic, but also if there is a major breach of the dikes or an accident in a chemical factory.

- Social and Political Stability: the undisrupted continued existence of a social climate in which groups of people live together without major conflict within the framework of the democratic state and shared core values. Social and political stability can be at risk if changes occur in the demographic structure of society (for example solidarity between generations), social cohesion and the degree of participation of the population in social processes.

The five interests are entwined; breach of one can lead to breach of other interests. For example, breach of the physical security (the fourth interest) can put pressure on 


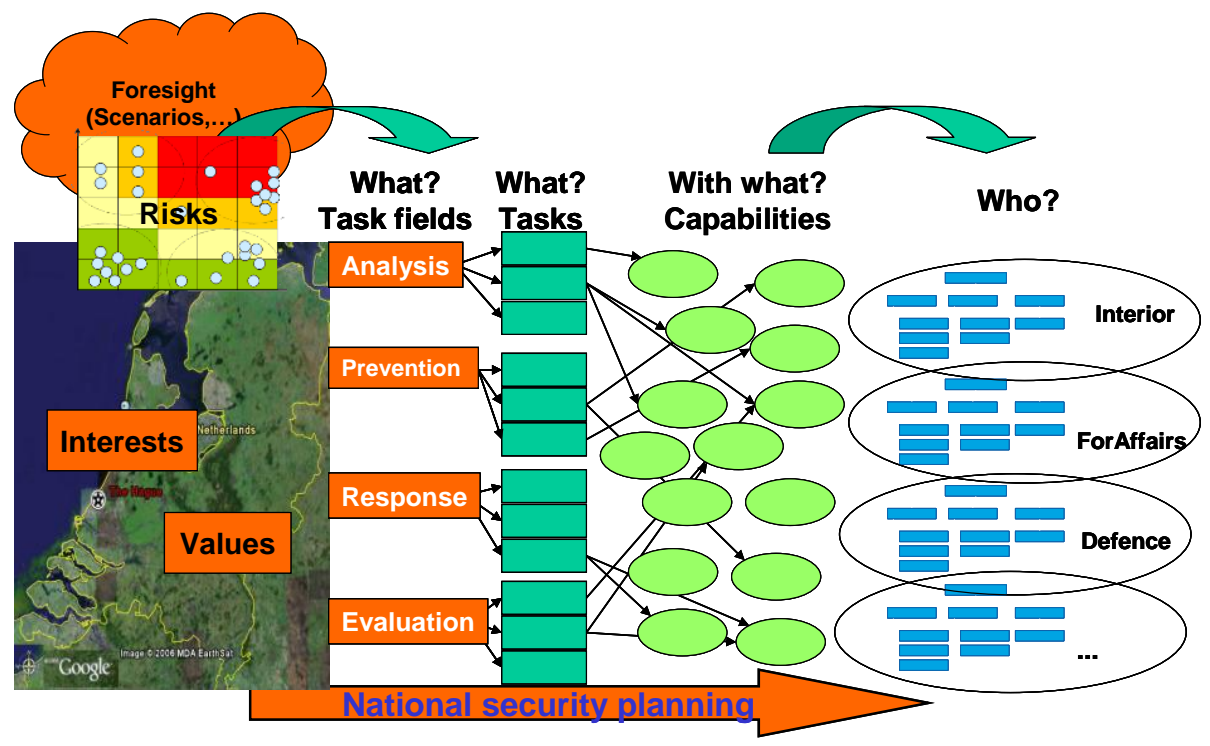

Figure 3: Methodology behind the National Strategy Making Process.

the fifth interest: social and political stability. At the same time, this interest can also be directly threatened - by breach of social cohesion, for example. The degree of social cohesion is the result of the binding power of the core values of the Dutch society. Breach of these values is the same as breach of the core of Dutch society. In protecting vital interests, the context within which justice can be done to these values has to be safeguarded.

But protection of national security also affects these core values in a different way. For example, freedoms and rights (such as privacy) can be at risk due to policies aimed at reinforcing national security. In that sense there is a dilemma: the protection of vital interests for society demands policy, while that same policy can affect the core values for individuals and groups in that society. When applying the working method for national security, a balance must be found in this respect, too.

Given these requirements for the national security strategy of the Netherlands, a lot of activities were started. First of all, there were self-evaluations to scan the status regarding themes that were supposed to be important for national security. Also, an international comparison and literature review was made and used to feed the methodological development of the strategy. In Figure 2, both the self-evaluation and the strategy methodology development approach are illustrated. 


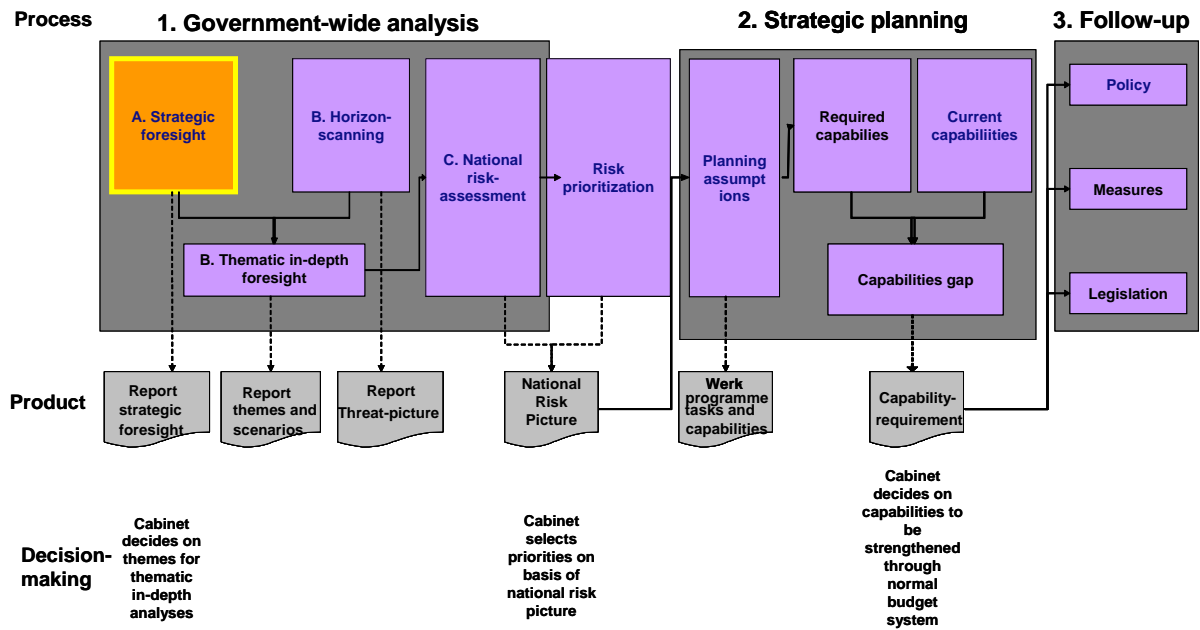

Figure 4: The National Security Strategy Process.

In general, the methodology is developed starting with interests and values combined with scenarios, deriving task-fields and tasks out of them. Next step is analysing what capabilities the government needs to address the risks foreseen and as a last step asking for the institutional question; who is able and willing to develop or maintain the necessary capabilities as a starting point for strategic planning.

All the elements of the national security strategy put in a logical process is called National Security Strategy. It consists of process, methods and products combined and communicated in a coherent way.

\section{Stage 1: Analysis of Threats and Assessment of Risks}

In order to protect the vital interests as best as possible, it is important to continually possess a clear picture of potential threats. The method of work therefore starts with analysis of the threats facing the Netherlands, assessment of the threats in terms of risks to vital interests and weighing of these risks vis-à-vis each other. At the end of this stage, the Cabinet will decide which risks are prioritised for detailed follow-up in the strategic planning stage.

\section{Stage 2: Strategic Planning}

In this stage the government determines which capabilities it would require to deal with the prioritised risks and which capabilities it already possesses and/or can expect from external parties, such as the business community, social organisations and inter- 


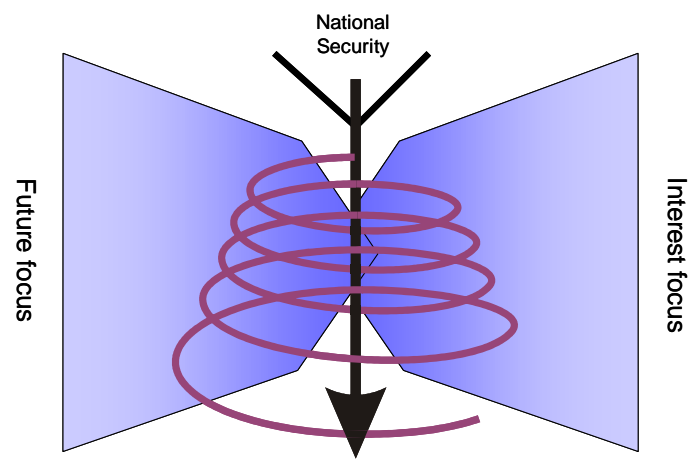

Figure 5: The Butterfly Foresight Model: Left Wing is Meta-Analysis; Right Wing - Policy Oriented Analysis Resulting in Themes for Risk Assessment.

national organisations. The Cabinet will then be given advice on, inter alia, the following issues: where is the government going to deploy resources (and where not) and in what stage of the security chain? The acceptability of choices is also considered.

\section{Stage 3: Follow-up}

Here, the political-administrative choices are developed into, e.g., policy, legislation and concrete measures.

The next paragraph explains in more detail how the foresight and risk analysis part of the methodology is being developed, since it is still under development.

It begins with foresight, long-term development analysis of themes that are of interest in positive or negative (chances and threats) ways to national security. These themes are identified and processed to make choices for further development and risk analysis. This is partly done via meta-analysis. Scenarios are collected worldwide, analysed by looking for drivers of changes and assessing them against the vital interest for national security. This is done in both long-term and short-term perspective. This is the 'rational'-process top-down-step done without direct influence of policy-oriented people.

And the last step is the 'policy'-oriented process. In this step, a bottom-up process is organised, involving policy people from government and agencies. Both processes are then combined and that results in the first draft of themes as input for the risk analysis and assessment phase.

Having analysed the possible themes for strategic planning, the themes will be studied in more depth by experts to develop a more basic understanding of the phenomena. 


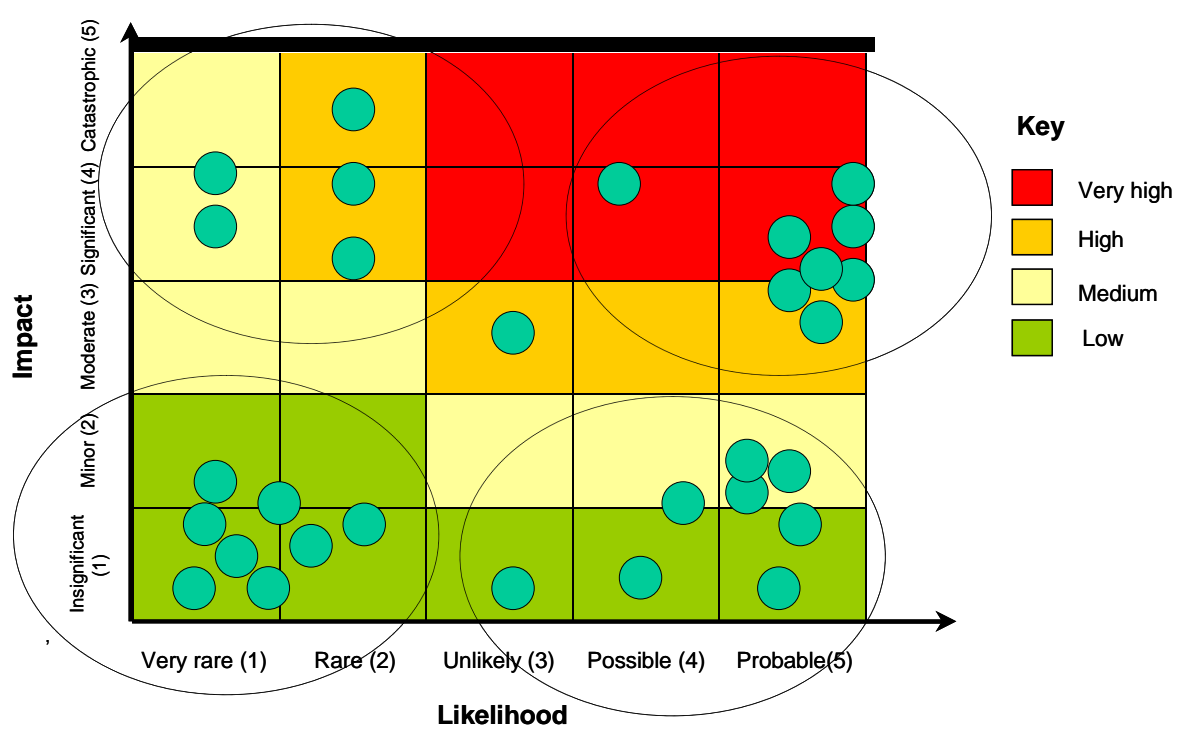

Figure 6: Risk Assessment Approach to National Security.

This study then forms the input for risk analysis and assessment. The risk assessment methodology is being developed at the moment. What it basically does is assessing likelihood and impact on national security. This is done via an all-hazards approach.

This risk assessment methodology provides a systematic method (leading to comparability), 'objectivisation' (also of the 'softer' aspects) and also government-wide (across stovepipes) approach. Additionally, it enables genuine prioritization (also for security investments). The results are then used as input for the government-wide strategic planning process.

\section{What Does the Strategic Planning Stage Provide?}

The results of the strategic planning stage will allow the Cabinet to decide whether a reinforcement of capabilities is required in view of the prioritised risks, and if so, in what areas and at what stage of the security chain. This reinforcement can be the responsibility of a specific department or of parties outside of the (national) government, but also of the country as a whole (e.g., a national reserve of resources to combat a pandemic). Strategic planning also allows for the identification of cross-links, not only within the government but also between the government and the parties outside of the government; this enables available resources to be used effectively. The Cabinet makes choices about how national security is reinforced: by developing or intensifying policy, adjusting the statutory instruments or by taking concrete meas- 


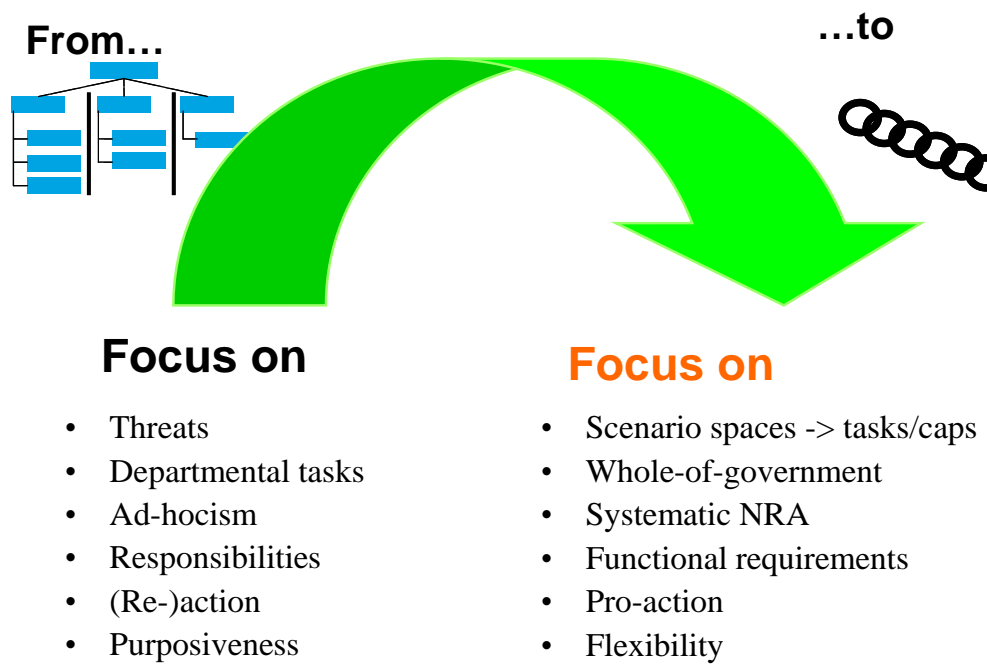

Figure 7: The National Strategy is Shifted from ... to.

ures. The need for reinforcing national security is always weighed up against the consequences thereof for other interests, e.g. the rights of individuals. In addition, the proposed measures and policy intensifications must be in proportion to the goal, both with regard to effectiveness and efficiency. In other words, the proportionality of the measures to reinforce national security is explicitly included in the consideration. ${ }^{10}$

Strategic planning provides insight into how the tasks could be optimally divided between national government, other authorities, social organisations and the private sector. In some sectors, private institutions are responsible for safeguarding continuity and offering an adequate response to all sorts of possible threats. One example of this is the telecommunications sector. Strategic planning is an instrument for clarifying and optimising the combined action between these parties; it systematically brings people, resources, plans and procedures together and clearly sets out what people can expect from each other. In addition, this creates a common frame of reference. ${ }^{11}$

\section{Concluding: Innovation in National Security Strategy is at Hand}

The path that is chosen in the Netherlands is a proactive one. It is based on the use of scenario spaces focussing on tasks and capabilities instead of focussing purely on threats; in addition, it is based also on a whole-of-government approach instead of departmental tasking and a systematic national risk assessment, which guarantees more flexibility and agility in the security strategy making process. 
Some of the direct advantages of the approach are already mentioned. Its first direct effect is a modern security strategy (more process than 'design') away from institutional debates. It is more a framework ('a living' capstone-document with basic principles) than a blueprint and therefore it has inherent flexibility. It is based on a to-bedeveloped if necessary hierarchy of strategic documents. The capability-based planning methods, foresights and risk assessments (systematic national risk assessment method) are being used in time as a government-wide method, which is helping in 'de-stovepiping' and is better securing the national security.

\section{Notes:}

1 National Security, Strategy and Work Programme 2007-2008 (The Hague, 2007).

2 The Economist, 20 March 1993, 106.

3 Constantinos C. Markides, eds., "In Search of Strategy," MIT Sloan Management Review 40, no. 3 (Spring 1999).

${ }^{4}$ Henry Mintzberg, The Rise and Fall of Strategic Planning (New York, NY: The Free Press, January 1994).

5 Henry Mintzberg, "The Fall and Rise of Strategic Planning," Harvard Business Review 72, no. 1 (January-February 1994): 107-114.

${ }^{6}$ Mintzberg, The Rise and Fall of Strategic Planning.

7 National Security, Strategy and Work Programme 2007-2008, 23.

${ }^{8}$ Henry Mintzberg, The Rise and Fall of Strategic Planning: Reconceiving Roles for Planning, Plans, Planners (Simon \& Schuster, 1993); Mintzberg, "The Fall and Rise of Strategic Planning."

9 National Security, Strategy and Work Programme, 16.

${ }^{10}$ National Security, Strategy and Work Programme, 24-25.

${ }^{11}$ National Security, Strategy and Work Programme, 24-25.

MICHEL RADEMAKER is Senior Policy Analyst and Secretary of the Hague Centre for Strategic Studies, The Hague, The Netherlands. He is leader of several programmes regarding security and intelligence. He is the leader of the HCSS team that supports The Netherlands government in developing and implementing the national security strategy. E-mail: michel.rademaker@hcss.nl. 